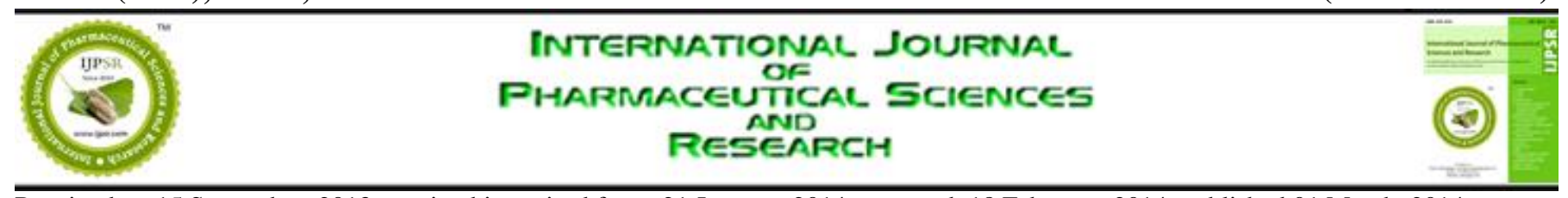

Received on 15 September, 2013; received in revised form, 21 January, 2014; accepted, 18 February, 2014; published 01 March, 2014

\title{
POTENTIAL HERBAL HEPATOPROTECTIVE PLANTS: AN OVERVIEW
}

\author{
Rajesh Kumar Soni*, Vihangesh Dixit, Raghuveer Irchhaiya and Shashi Alok
}

Department of Pharmacognosy, Bundelkhand University, Jhansi, Uttar Pradesh, India

Keywords:

Liver disease, hepatoprotective herb, hepatoprotective plants

Correspondence to Author:

Rajesh Kumar Soni

Department of Pharmacognosy, Bundelkhand University, Jhansi, Uttar Pradesh, India

E-mail: rajeshsoni1987@gmail.com

\begin{abstract}
Hepatic diseases (Liver diseases) are a major worldwide health problem, with high endemicity in developing countries. Hepatic disease is a term for a collection of conditions, diseases, and infections that affect the cells, tissues structures, or functions of the liver. Liver has a wide range of functions, including detoxification, protein synthesis, and production of biochemical necessary for digestion and synthesis as well as breakdown of small and complex molecules, many of which are necessary for normal vital functions. There are no specific allopathic medicines used as hepatoprotective, although different research works are going on some drug. Herbal drugs are more widely used than allopathic drugs as hepatoprotectives because they are inexpensive, have better cultural acceptability, better compatibility with the human body and minimal side effects. The present review discusses different types of recently herbal plants containing hepatoprotective activity.
\end{abstract}

INTRODUCTION: Liver is a vital organ of paramount importance involved in the maintenance of metabolic functions and detoxification of the exogenous and endogenous challenges like xenobiotics, drugs, viral infections and chronic alcoholism ${ }^{1}$.

Diverse homeostatic mechanisms are affected if liver function is impaired, with potentially serious consequences. About 20, 000 deaths occur every year due to liver diseases. Hepatocellular carcinoma is one of the ten most common tumors in the world with over 2, 50,000 new cases each year.

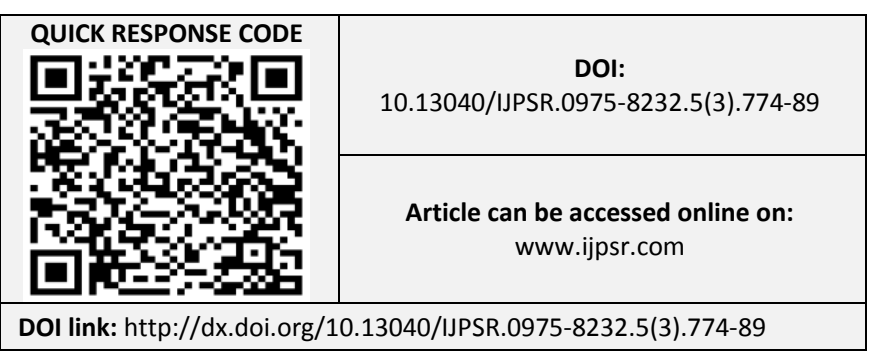

Although viruses are the main cause of liver diseases, excessive drug therapy, environmental pollution and alcoholic intoxication are not uncommon. Liver disease is a worldwide problem; Conventional drugs used in the treatment of liver diseases are sometimes inadequate and can have serious adverse effects.

Herbal medicines are in great demand in the developed as well as developing countries for primary healthcare because of their wide biological and medicinal activities, higher safety margins and lesser costs ${ }^{2}$.

Modern drugs have very little to offer for alleviation of hepatic ailments, whereas most important representatives of phytoconstituents used for liver diseases chiefly on regional basis include drugs like silymarine (Silybum marianum) and catechin (Anacardium occidentalis) in Europe, Glycyrrhizin (Glycyrrhiza glarbra) in Japan and chizandrins (Schizandra chinesis) in China ${ }^{3}$. 
The Indian traditional medicine like Ayurvedic, Siddha and Unani are predominantly based on the use of plant materials. Herbal drugs have gained importance and popularity in recent years because of their safety, efficacy and cost effectiveness. The association of medical plants with other plants in their habitat also influences their medicinal values in some cases. One of the important and well documented uses of plant products is their use as hepatoprotective agents. Hence, there is an ever increasing need for safe hepatoprotective agent ${ }^{4}$.

A. Herbal hepatoprotective plants: Herbal-based therapeutics for liver disorders has been in use in India for a long time and has been popularized world over by leading pharmaceuticals. Despite the significant popularity of several herbal medicines in general, and for liver diseases in particular, they are still unacceptable treatment modalities for liver diseases. The limiting factors that contribute to this eventuality are lack of standardization of the herbal drugs, lack of identification of active ingredients/principles, lack of randomized controlled clinical trials (RCTs) and lack of toxicological evaluation. The use of natural remedies for the treatment of liver diseases has a long history, starting with the Ayurvedic treatment, and extending to the Chinese, European and other systems of traditional medicines.

The $21^{\text {st }}$ century has seen a paradigm shift towards therapeutic evaluation of herbal products in liver disease models by carefully synergizing the strengths of the traditional systems of medicine with that of the modern concept of evidence-based medicinal evaluation, standardization and randomized placebo controlled clinical trials to support clinical efficacy ${ }^{5}$. A large number of plants and formulations have been claimed to have hepatoprotective activity. Nearly 160 phytoconstituents from 101 plants have been claimed by Pharmacopeia Foundation to possess liver protecting activity. In India, more than 87 plants are used in 33 patented and proprietary multi-ingredient plant formulations. In spite of the tremendous advances made, no significant and safe Hepatoprotective agents are available in modern therapeutics.
Therefore, due importance has been given globally to develop plant-based hepatoprotective drugs, effective against a variety of liver disorders ${ }^{6}$.

\section{B. Hepatoprotective activity reported on following plant}

1. Andrographis paniculata: Andrographolide active constituent of Andrographis paniculata (Family of Acanthaceae) antagonized the toxic effects of paracetamol on certain enzymes (SGOT, SGPT and ALP) in serum as well as in isolated hepatic cells as tested by trypan blue exclusion and oxygen uptake tests, in a significant dose dependent $(0.75-12 \mathrm{mg} / \mathrm{kg}$ p.o. $x$ 7days) manner 7 . Neoandrographolide increase GSH, glutathione 5-transferase, glutathione peroxidase, SOD and LPO level ${ }^{8,9}$.

2. Anoectochilus formosanus: The aqueous Extracts (AFEW-2) of fresh whole plant of Anoectochilus formosanus (Family of Orchidaceae) at dose $130 \mathrm{mg} / \mathrm{kg}$ showed inhibition of chronic hepatitis (induced by $\mathrm{CCl} 4)$ in mice by reducing SGPT and hepatic hydroxyproline level. It also diminished the hypoalbuminemia and splenomegaly. In an in vitro study, the LD50 values for $\mathrm{H} 2 \mathrm{O} 2$ induced cytotoxicity in normal liver cellswere significantly higher after kinsenoside (isolated from AFEW-2) pretreatment at the dose 20-40 $\mathrm{ug} / \mathrm{ml}^{10}$.

3. Azadirachta indica: The effect of Azadirachta indica leaf (Family of Meliaceae) extract on serum enzyme levels (glutamate oxaloacetate transaminase, glutamate pyruvate transaminase, acid phosphatise and alkaline phosphatase) elevated by paracetamol in rats was studied with a view to observe any possible hepatoprotective effect of this plant. It is stipulated that the extract treated group was protected from hepatic cell damage caused by paracetamol induction. The findings were further confirmed by histopathological study of liver. The antihepatotoxicaction of picroliv seems likely due to an alteration in the biotransformation of the toxic substances resulting in decreased formation of reactive metabolites ${ }^{11}$. 
4. Aerva Lanata: The hydroalcoholic extract of Aerva lanata (Family of Amaranthaceae) $(600 \mathrm{mg} / \mathrm{kg})$ was administered orally to the animals with hepatotoxicity induced by paracetamol $(3 \mathrm{gm} / \mathrm{kg})$. Silymarin $(25 \mathrm{mg} / \mathrm{kg})$ was given as reference standard. All the test drugs were administered orally by suspending in $0.5 \%$ Carboxy methyl cellulose solution. The plant extract was effective in protecting the liver against the injury induced by paracetamol in rats. This was evident from significant reduction in serum enzymes alanine aminotransferase (ALT), aspartate aminotransferase (AST), alkaline phosphatase (ALP) and bilirubin ${ }^{12}$.

5. Acacia catechu: The ethyl acetate extract of Acacia Catechu (Family of Leguminosae) of acute liver damage in albino rats was induced by a single subcutaneous administration of 4 $\mathrm{ml} / \mathrm{kg}$ dose of $50 \% \mathrm{v} / \mathrm{v}$ of carbon tetrachloride in olive oil and the chronic liver damage by subcutaneous injection of $50 \% \mathrm{v} / \mathrm{v}$ carbon tetrachloride in olive oil at the dose of $2 \mathrm{ml} / \mathrm{kg}$ twice a week for 14 days. The hepatoprotective activity was monitored biochemically by estimating serum hansaminase, serum alkaline phosphatase and serum bilirubin in both the cases after intraperitoneal injection of ethyl acetate extract of "katha" (250 mg/kg). The histopathological changes of liver samples were compared with that of control. The extract of "katha" inhibited carbon tetrachloride induced liver toxicity in albino rats at $250 \mathrm{mg} / \mathrm{kg}$, b.w. as assessed by the biochemical and histopathological values ${ }^{13}$.

6. Alocasia indica: The hydroalcoholic extract of Alocasia indica (Family of Araceae) (250 and $500 \mathrm{mg} / \mathrm{kg}$ ) effectively inhibited $\mathrm{CCl}_{4}$ and paracetamol induced changes in the serum marker enzymes, cholesterol, serum protein and albumin in a dose-dependent manner as compared to the normal and the standard drug silymarin-treated groups. Hepatic steatosis, fatty infiltration, hydropic degeneration and necrosis observed in $\mathrm{CCl}_{4}$ and paracetamoltreated groups were completely absent in histology of the liver sections of the animals treated with the extracts ${ }^{14}$.
7. Amaranthus spinosus: The $50 \%$ ethanolic extract of whole plant of Amaranthus spinosus (ASE) (Family of Amaranthaceae) was evaluated against carbon tetrachloride $\left(\mathrm{CCl}_{4}\right)$ induced hepatic damage in rats. The ASE at dose of 100, 200 and $400 \mathrm{mg} / \mathrm{kg}$ were administered orally once daily for fourteen days. The substantially elevated serum enzymatic levels of serum glutamate oxaloacetate transaminase (AST), serum glutamate pyruvate transaminase (ALT), serum alkaline phosphatase (SALP) and total bilirubin were restored towards normalization significantly by the ASE in a dose dependent manner. Higher dose exhibited significant hepatoprotective activity against carbon tetrachloride induced hepatotoxicity in rats. The biochemical observations were supplemented with histopathological examination of rat liver sections.

Meanwhile, in vivo antioxidant activities as malondialdehyde (MDA), hydroperoxides, reduced glutathione (GSH), superoxide dismutase (SOD) and catalase (CAT) were also screened which were also found significantly positive in a dose dependent manner. The results of this study strongly indicate that whole plants of A. spinosus have potent hepatoprotective activity against carbon tetrachloride induced hepatic damage in experimental animals ${ }^{15}$.

8. Amorphophallus paeoniifolius: The methanol and aqueous extracts of Amorphophallus paeoniifolius (Family of Araceae tubers against paracetamol induced liver damage in rats. glutamic pyruvic transaminase (sGPT), serum glutamic oxaloacetic transaminase (sGOT) and serum alkaline phosphatase (sALP), serum bilirubin (SB) and histopathological change. steroids and flavonoids.

Pre-treatment of the rats with methanol and aqueous extract prior to paracetamol administration caused a significant reduction in the values of sGOT, sGPT, sALP and sB $(\mathrm{P}<0.01)$ almost comparable to the silymarin and Liv-52. The hepatoprotective was confirmed by histopathological examination of the liver tissue of control and treated animals ${ }^{16}$. 
9. Aloe barbadensis: The shade dried aerial parts of Aloe barbadensis (Family of Liliaceae) were extracted with petroleum ether, chloroform and methanol. The plant marc was extracted with distilled water. All the extracts were evaluated for hepatoprotective activity on limited test models as hexobarbitone sleep time, zoxazolamine paralysis time and marker biochemical parameters. Petroleum ether and chloroform extract were observed to be devoid of any hepatoprotective activity. Out of two active extracts (methanol and aqueous), the most active aqueous extract was studied in detail. Aqueous extract showed significant hepatoprotective activity against bile duct ligation induced hepatotoxicity as evident by restoration of serum transaminases, alkaline phosphatase, bilirubin and triglycerides.

Hepatoprotective potential was confirmed by the restoration of lipid peroxidation, glutathione, glucose-6-phosphatase and microsomal aniline hydroxylase and amidopyrine $\mathrm{N}$-demethylase towards near normal. Histopathology of the liver tissue further supports the biochemical findings confirming the hepatoprotective potential of aqueous extract. The aqueous extract of Aloe barbadensis is significantly capable of restoring integrity of hepatocytes indicated by improvement in physiological parameters, excretory capacity of hepatocytes and also by stimulation of bile flow secretion. Aqueous extract did not show any sign of toxicity up to oral dose of $2 \mathrm{~g} / \mathrm{kg}$ in mice ${ }^{17}$.

10. Astragalus kahiricus: The hepatoprotective activity of the ethanol extract of Astragalus kahiricus (Family of Fabaceae) roots against ethanol-induced liver apoptosis was evaluated and it showed very promising hepatoprotective actions through different mechanisms. The extract counteracted the ethanol-induced liver enzymes leakage and glutathione depletion. In addition, it demonstrated anti-apoptotic effects against caspase-3 activation and DNA fragmentation that were confirmed by liver histopathological examination. Moreover, the phytochemical study of this extract led to the isolation of four cycloartane-type triterpenes identified as astrasieversianin, astramembrannin, astrasieversianin and cycloastragenol.
The structures of these isolates were established by HRESI-MS and 1D and 2D NMR experiments. The antimicrobial, antimalarial, and cytotoxic activities of the isolates were further evaluated, but none of them showed any activity ${ }^{18}$.

11. Barleria cristata: The ethanolic leaves extract of Barleria cristata (Family of Acanthaceae) is evaluated for hepatoprotective activity by using CCl4 $(0.7 \mathrm{ml} / \mathrm{kg}$, i.p) induced liver damage in male Wistar albino rats at a dose of 100 and $200 \mathrm{mg} / \mathrm{kg}$ body weight. The ethanolic extract of $B$. cristata significantly $(\mathrm{P}<0.001)$ decreases the serum levels of hepato specific enzymes like SGPT, SGOT, ALP and total bilirubin levels, total protein levels, cholesterol and triglycerides levels.

Silymarin (25 $\mathrm{mg} / \mathrm{kg}), \quad$ a known hepatoprotective drug used for comparison exhibited significant activity $(\mathrm{P}<0.001)$. The extract did not show any mortality up to a dose of $2000 \mathrm{mg} / \mathrm{kg}$ body weight. Histopathological analysis confirmed the biochemical investigations. The results indicate that Ethanolic Extract of $B$. cristata possess hepatoprotective property which may be due to the presence of alkaloids and flavonoids ${ }^{20}$.

12. Betula utilis: The ethanolic and aqueous bark extract of Betula utilis (Family of Betulaceae) is evaluated for in vivo hepatoprotective at dose 100 and $200 \mathrm{mg} / \mathrm{kg}$ body weight was carried out agains D-galactosamine, which on dose of $400 \mathrm{mg} / \mathrm{kg}$ body weight i.p. induces liver injury in rats. The hepatocytes challenged with $50 \mu \mathrm{l}$ of $10 \mathrm{mM}$ solution of $\mathrm{D}$-galN. The group to which toxicant was added showed a significant increase in the ASAT, ALAT, and ALP enzyme level when compared to the normal.

All the biochemical parameters were restored to normal significantly. Minimum restoration was observed at $62.5 \mu \mathrm{g} / \mathrm{ml}$ in both the plant extract and Betula utilis extract protects the liver from severe damage caused by $\mathrm{D}$-galactosamine and may serve as a useful adjuvant in several clinical conditions associated with liver damage 21 . 
13. Boerhavia Diffusa: The hepatoprotective activity of different parts of Boerhavia diffusa Linn. (Family of Nyctaginaceae) such as root and aerial parts against ibuprofen (IB) induced hepatotoxicity in Wistar albino rats. Boerhavia diffusa L. is one of the well-known folklore medicinal plants. The administration of ibuprofen $(500 \mathrm{mg} / \mathrm{kg}$. b. wt.) produced significant changes in the normal hepatic cells, resulting in the formation of gastric lesions, centrilobular necrosis, vacuolization, and hepatomegaly. The adverse effect of ibuprofen was reflected in the levels of biochemical parameters of liver marker enzymes such as ALT, AST, ALP, and bilirubin.

The activities of natural antioxidant enzymes like superoxide dismutase (SOD), catalase (CAT), glutathione peroxidase (GPx), and Glutathione-S-transferase (GST) were decreased significantly. The methanol extract $(85 \%)$ of the root and aerial part of Boerhavia diffusa L. $(500 \mathrm{mg} / \mathrm{kg}$. b. wt.) produced remarkable changes in affected hepatic cell architecture and restored nearly normal structure and functions of hepatic cells. Similarly the different parts of the Boerhavia diffusa L. (500 mg/kg. b. wt.) restored the altered biochemical parameters of liver marker enzymes close to normal control levels. The observed results show the root of Boerhavia diffusa L. possesses more hepatoprotective efficacy than the aerial part of the same plant. The results suggest that the hydro alcoholic (15:85\%) extract of Boerhavia diffusa L. possesses significant potential effect as a hepatoprotective agent ${ }^{22}$.

14. Cinnamomum zeylanicum: The protective effect of $80 \%$ ethanolic extract of bark of Cinnamomum zeylanicum (Family of Lauraceae) against carbon tetrachloride $\left(\mathrm{CCl}_{4}\right)$ induced liver damage in male Wistar rats. Administration with cinnamon extracts (0.01, 0.05 and $0.1 \mathrm{~g} / \mathrm{kg}$ ) for 28 days significantly reduced the impact of $\mathrm{CCl}_{4}$ toxicity on the serum markers of liver damage, aspartate aminotransferase, alanine aminotransferase and alkaline phosphatase. In addition, treatment of cinnamon extract resulted in markedly increased the levels of superoxide dismutase and catalase enzymes in rats.
The histopathological studies in the liver of rats also supported that cinnamon extract markedly reduced the toxicity of $\mathrm{CCl}_{4}$ and preserved the histoarchitecture of the liver tissue to near normal $^{23}$.

15. Chenopodium album: The different extracts (Peterolium ether extract, Ethyl Acetate extract and Methanol extract) of Chenopodium album (Family of Chenopodiaceae) aerial parts were studied for its hepatoprotective effect on $\mathrm{CCl} 4$ induced hepatotoxic rats. The extracts were found to decrease significantly $\mathrm{CCl}_{4}$-induced elevation of SGOT, SGPT, bilirubin and total cholesterol. But it increased HDL cholesterol level and liver weight with respect to $\mathrm{CCl}_{4}$ toxic rats. Histopathological profiles showed that out of all the extracts, methanol extract had significant protective effect against $\mathrm{CCl}_{4}$ induced liver injury which is comparable with the standard drug Silymarin (25 mg/kg, p.o.) ${ }^{24}$.

16. Cienfuegosia digitata: The hepatoprotective effects of aqueous acetone extract of Cienfuegosia digitata Cav. (Family of Malvaceae) an herbal plant used in Burkina Faso to treat traditionally liver disease in albinos Wistar rats. Animals received by gavage 25,50 and $100 \mathrm{mg} / \mathrm{kg}$ body weight of extract daily for a period of 28 days. Control groups received alcohol $35 \%$ and water. In vivo administration of $35 \%$ ethanol for a period of 28 days in rats showed an activity of liver marker enzymes (AST, ALT, ALP and GGT), triglycerides, total cholesterol, total bilirubin and direct bilirubin in serum compared with rats which received water (control water).

However, administration of $35 \%$ ethanol along with aqueous acetone extract decreased the activities of liver markers enzyme in serum comparatively to the control water group $(\mathrm{p}<0.05$ or $\mathrm{p}<0.01)$. We noticed that extract at a dose of $100 \mathrm{mg} / \mathrm{kg}$ body weight was highly effective than 25 and $50 \mathrm{mg} / \mathrm{kg}$ body weight compared to the control water group (ALT and ALP; $\mathrm{p}>0.05$ and $\mathrm{p}<0.05$ ). This study revealed that Cienfuegosia digitata presents a hepatoprotective potential and this plant could be traditionally exploited in the treatment of liver disease particularly hepatitis B in Burkina Faso ${ }^{25}$. 
17. Citrullus colocynthis: The in-vivo hepatoprotective effect of the ethanolic extracts of Citrullus colocynthis (Linn.); (Family of Cucurbitaceae) against paracetamol induced hepatotoxicity in albino rats. Swiss Albino rats of either sex were used, divided into six groups with six in each group. The animals were maintained under normal control, which were given distilled water only. The animals received paracetamol 50, $100 \quad 200 \& 500 \mathrm{mg} / \mathrm{kg}$ body weight per day for 7 days (p.o). The animals were treated with Silymarin $(100 \mathrm{mg} / \mathrm{kg}$ p.o) which served as standard and animals were intoxicated with paracetamol. Histopathological findings, different hepatic biochemical parameters viz. AST, ALT, ALP, Total bilirubin, Total cholesterol, Triglycerides, \& the body weight before $\&$ after treatment were evaluated to investigate the hepatoprotective activity.

Paracetamol induced a significant rise in AST, ALT, ALP, Total Bilirubin, Total Cholesterol, Triglycerides. Administration of $200 \mathrm{mg} / \mathrm{kg}$ body weight of ethanolic extract of $C$. colocynthis effectively reduced these pathological damages caused by paracetamol intoxication. In addition to serum parameters treatment of $200 \mathrm{mg} / \mathrm{kg}$ bw of ethanolic extract of $C$ colocynthis also promotes the body weight in albino rats ${ }^{26}$.

18. Citrullus Lanatus: The protective effect of citrullus lanatus (Family of Cucurbitaceae) seed oil against CCl4 induced hepatic damage in rat. The hepatoprotective was on carbon tetrachloride induced hepatotoxicity in rats by estimated serum hepatic enzyme levels and hisopathological study of liver tissues. Citrullus lanatus seed oil; CLSO (125mg) and CLSO (250mg) were administered orally for 10 days in rats and compared with standard silymarin $(100 \mathrm{mg} / \mathrm{kg})$ orally. The results showed significant decrease in serum ALT, AST and ALP levels treated groups which were increased due to $\mathrm{CCl} 4$ induced liver damage are comparable with standard drug. Histopathological study of liver tissue ravels the hepatoprotective activity of Citrullus lanatus seed oil ${ }^{27}$.
19. Cnidoscolus Chayamansa: The effect of ethanolic extract of Cnidoscolus chayamansa (Family of Euphorbiaceae) leaves in experimentally drug induced hepatitis in rats. Rats were divided into five different groups each having six. Group 1 served as a control, Group 2 received Rifampicin (RIF) (100 $\mathrm{mg} / \mathrm{kg}$, i.p.) and co-administered with Isoniazid (INH) $(100 \mathrm{mg} / \mathrm{kg}$, i.p.), in sterile water, group 4 and 5 served as extract treatment groups and received $200 \& 400 \mathrm{mg} / \mathrm{kg}$, orally, ethanolic extract of Cnidoscolus chayamansa and group 3 served as standard group and received Silymarin $2.5 \mathrm{mg} / \mathrm{kg}$ orally. All the treatment protocols followed 21 days and after which rats were sacrificed, blood and liver were taken for biochemical and histological studies, respectively. The Rifampicin (RIF) and Isoniazid INH treated group rats (G2) showed variable increase in serum AST, ALT, ALP, total protein and total bilirubin levels.

Administration of ethanolic extracts of Cnidoscolus chayamansa significantly prevented Rifampicin-Isoniazid-induced elevation in the levels of serum diagnostic liver marker enzymes aspartate amino transferase (AST), alanine amino transferase (ALT) and alkaline phosphatase (ALP) level in experimental groups of rats. Moreover, total protein and total albumin levels were significantly increased in treatment groups. The effect of extract was compared with a standard drug, Silymarin. The changes in biochemical parameters were supported by histological profile. It is concluded that the ethanolic extract of Cnidoscolus chayamansa protects against rifampicin and Isoniazid-induced oxidative liver injury in rats ${ }^{28}$.

20. Chrysanthemum indicum: The hepatoprotective effects of Chrysanthemum indicum L. (Family of Asteraceae) flower significantly reduced the levels of GOT $(60.1 \%, \mathrm{P}=0.000)$ and GPT $(64.5 \%, \mathrm{P}=0.000)$ compared with the vehicle control group (CCl4 alone). Hepatoprotective activities were evaluated at 250 to $1000 \mu \mathrm{g} / \mathrm{mL}$ concentrations by an in vitro assay using normal human hepatocytes (Chang cell) and hepatocellular carcinoma cells (HepG2) against CCl4-induced cytotoxicity. 
Cytochrome P450 2E1, which is a key indicator of hepatic injury, was detected by western blot analysis using rabbit polyclonal anti-human CYP2E1 antibody. An in vivo hepatoprotective activity assay was performed at 1000 to 4000 $\mu \mathrm{g} / \mathrm{mL}$ concentrations on $\mathrm{CCl} 4$-induced acute toxicity in rats, and the serum levels of glutamic oxaloacetic transaminase (GOT), glutamic pyruvic transaminase (GPT), alkaline phosphatase (ALP) and lactate dehydrogenase $(\mathrm{LDH})$ were determined by standard enzyme assays ${ }^{29}$.

21. Curcuma longa: The hepatoprotective effect of Curcuma longa rhizome ethanolic extract (CLRE) (Family of Zingiberaceae) was measured in a rat model of thioacetamideinduced liver cirrhosis over 8 weeks. Hepatic cytochrome P450 2E1 and serum levels of TGF- $\beta 1$ and TNF- $\alpha$ were evaluated. Oxidative stress was measured by malondialdehyde, urinary 8-hydroxyguanosine and nitrotyrosine levels. The protective activity of CLRE freeradical scavenging mechanisms were evaluated through antioxidant enzymes. Protein expression of pro-apoptotic Bax and antiapoptotic Bcl-2 proteins in animal blood sera was studied and confirmed by immunohistochemistry of $\mathrm{Bax}, \mathrm{Bcl} 2$ proteins and proliferating cell nuclear antigen ${ }^{30}$.

22. Cyperus articulates: The hepatoprotective activity of the methanol extract of Cyperus articulatus Linn. (MECA) (Family of Cyperaceae) against paracetamol induced liver damage in rats. Hepatotoxicity was induced in Wistar rats by oral administration of paracetamol $(640 \mathrm{mg} / \mathrm{kg}$ suspended in $1 \%$ carboxy methyl cellulose), once during the 16 days treatment period. MECA was administered orally at the doses of 200 and $400 \mathrm{mg} / \mathrm{kg}$ daily for 16 days.

Silymarin $(25 \mathrm{mg} / \mathrm{kg})$ was used as standard drug. Hepatoprotective activity was evaluated by the biochemical estimation of liver function parameters (SGPT, SGOT, ALP, total protein and total billirubin), antioxidant assays of liver homogenate (lipid peroxidation, reduced glutathione content, superoxide dismutase and catalase activity) and histological study of liver tissue.
In MECA treated animals, the toxic effect of paracetamol was controlled significantly by restoration of the biochemical parameters, such as, SGPT, SGOT, ALP, total protein and total billirubin, as well as by the improvement of the antioxidant status to/towards near normal values. Histology of the liver sections of the animals treated with the extracts showed the presence of normal hepatic cords, absence of necrosis and fatty infiltration, which further evidenced the hepatoprotective activity of MECA. The results show that the methanol extract of Cyperus articulatus possesses hepatoprotective activity against paracetamol induced hepatotoxicity in rats 31 .

23. Desmodium oojeinense: The hepatoprotective activity of ethanolic extract of Desmodium oojeinense(Roxb) H Ohashi(Family of Fabaceae) against Paracetamol induced Hepatotoxicity in rats. Ethanolic extract showed significant hepatoprotective effect by lowering the serum levels of various biochemical parameters such as SGOT, SGPT, ALP, total Bilirubin and by increasing the levels of total Protein, in the selected model. These biochemical observations were in turn confirmed by histopathological examinations of liver sections and are comparable with the standard hepatoprotective drug Silymarin (100mg/kg bodyweight i.p.) which served as a positive control. Our findings suggested that the ethanolic extract of Desmodium oojeinense (Roxb) H Ohashi possesses the hepatoprotective activity ${ }^{32}$.

24. Ecbolium viride: The ethanolic extract of leaves of Ecbolium viride (Family of Acanthaceae) against $\mathrm{CCl}_{4}$ induced liver damage in rats. The extract (100 and 200 $\mathrm{mg} / \mathrm{kg}$ ) was administered orally to the animals with hepatotoxicity induced by $\mathrm{CCl}_{4}(1 \mathrm{ml} / \mathrm{kg})$. Silymarin $(25 \mathrm{mg} / \mathrm{kg})$ was given as reference standard. All the test drugs were administered orally by equal volume of olive oil $(50 \% \mathrm{v} / \mathrm{v})$. After the drug treatment all the animals were sacrificed by cervical dislocation. Blood was collected from the carotid artery and was allowed to clot for $45 \mathrm{~min}$ at room temperature; serum was separated by centrifugation at 2500 rpm for $15 \mathrm{~min}$, used for the estimation of various biochemical parameters namely GOT, 
GPT, ALP, ACP and Bilirubin. Biochemical parameters such as Serum Glutamate Pyruvate Transaminase (SGPT), Serum Glutamate Oxaloacetate Transaminase (SGOT), Serum Alkaline Phosphatase (SALP), Serum acid Phosphatase (SACP), Liver, and Bilirubin (total $\&$ direct) were determined ${ }^{33}$.

25. Elaeis guineensis: The in vitro antioxidant and in vivo hepatoprotective activity of $E$. guineensis (Family of Arecaceae) against experimentally induced liver injury through serum analysis. Serum activity was measured by monitoring the levels of aspartate aminotransferase (AST), alanine aminotransferase (ALT) and billirubin. The extract exhibits in vitro antioxidant activity with an IC50 value of $814 \mu \mathrm{g} / \mathrm{mL}$ in the DPPH radical scavenging activity and $37.48 \mu \mathrm{g} / \mathrm{mL}$ in xanthine oxidase inhibitory (XOI) activity. The results of the paracetamolinduced liver toxicity experiments indicated that mice treated with the E. guineensis leaf extract $(200 \mathrm{mg} / \mathrm{kg})$ showed a significant decrease in ALT, AST, and bilirubin levels, which were all elevated in the paracetamol treated group $(p<0.01)$. The hepatoprotective action is likely related to its potent in vitro antioxidant activity ${ }^{34}$.

26. Elephantopus scaber: The protective effect of E. scaber (Family of Asteraceae) on ethanolinduced liver damage is still unclear. In this study, we have compared the in vivo hepatoprotective effect of E. scaber with Phyllanthus niruri on the ethanol-induced liver damage in mice. The total phenolic and total flavanoid content of E. scaber ethanol extract were determined in this study. Accelerating serum biochemical profiles (including AST, ALT, ALP, triglyceride, and total bilirubin) associated with fat drop and necrotic body in the liver section were observed in the mice treated with ethanol.

Low concentration of $E$. scaber was able to reduce serum biochemical profiles and the fat accumulation in the liver. Furthermore, high concentration of E. scaber and positive control $P$. niruri were able to revert the liver damage, which is comparable to the normal control. Added to this, E. scaber did not possess any oral acute toxicity on mice.
These results suggest the potential effect of this extract as a hepatoprotective agent towardsethanol induced liver damage without any oral acute toxicity effect. These activities might be contributed, or at least in part, by its high total phenolic and flavonoid contents ${ }^{35}$.

27. Ficus bengalensis: The hepatoprotective potentials of the ethanolic extract of the Ficus bengalensis (Family of Moraceae) leaves were tested against carbon tetrachloride $\left(\mathrm{CCl}_{4}\right)$ and ethanol -induced liver damage in rats. Changes in the levels of biochemical markers of hepatic injury viz; -aspartate aminotransferase (AST), alanine aminotransferase (ALT), total protein (TP) and total albumin (TA) were determined in both treated and control groups of rats. The effects of the extracts were compared with that of silymarin $(50 \mathrm{mg} / \mathrm{kg})$. The results showed that $\mathrm{CCl}_{4}$, and ethanol elevates the levels of AST, ALT and decreased levels of TP and TA. Treatment with the ethanolic extract of Ficus bengalensis (EEFB) 100,200 and $400 \mathrm{mg} / \mathrm{kg}$ ameliorated the effects of the hepatoxins and significantly $(\mathrm{P}<0.05)$ reduced the elevated levels of the biochemical marker enzymes ${ }^{36}$.

28. Feronia limonia: The hepatoprotective effect of the ethanolic extract of fruit pulp of Feronia limonia (Linn.) (Family of Rutaceae) against paracetamol induced hepatotoxicity in albino rats. Albino rats of either sex weighing between 150-200 g were randomly assigned into six groups of six animals each. Group 1-Normal control: The animals were maintained as normal control, which were given distilled water only. Group 2- Induction of hepatotoxicity: The animals received paracetamol $500 \mathrm{mg} / \mathrm{kg}$ bw (p.o) at every $72 \mathrm{~h}$ for 10 Days. Groups 3 to 5: Animals received ethanolic extract of fruit pulp of Feronia limonia at 100, $200 \& 300 \mathrm{mg} / \mathrm{kg}$ bw/day for 7 days (p.o). Group 6: The animals were treated with Silymarin $(100 \mathrm{mg} / \mathrm{kg}$ p.o $)$ which served as standard. Groups 3 to 6 were intoxicated with paracetamol $(500 \mathrm{mg} / \mathrm{kg}$ bw) $1 \mathrm{~h}$ before the administration of extract or Silymarin for 10 days. Different hepatic biochemical parameters viz. AST, ALT, ALP, Total Bilirubin, Total cholesterol, Triglycerides \& the body weights before \& after treatment were evaluated to investigate the hepatoprotective activity. 
It was observed that in paracetamol intoxicated group; total cholesterol, total bilirubin, triglycerides, AST, ALT, ALP activities were significantly increased as compared to control group. Administration of $300 \mathrm{mg} / \mathrm{kg}$ bw of ethanolic extract of Feronia limonia L. effectively reduced these pathological damages caused by paracetamol intoxication. In addition to serum parameters treatment of $300 \mathrm{mg} / \mathrm{kg}$ bw of ethanolic extract of Feronia limonia L. also promotes the body weight in albino rats respectively. Inspite of tremendous advances in modern medicine, there are not many effective drugs available that stimulate liver function, offer protection to the liver from damage or help to regenerate hepatic cells. It may be concluded that the ethanolic extract of Feronia limonia L. Showed hepatoprotective activity against paracetamol induced hepatotoxicity in albino rats. Thus, in future this herbal formulation may be used as a strong hepatoprotective drug ${ }^{37}$.

29. Garcinia indica: The protective effects of aqueous extracts of the fruit rind of Garcinia indica (GIE) (Family of Clusiaceae/Guttiferae) on ethanol-induced hepatotoxicity and the probable mechanisms involved in this protection were investigated in rats. Liver damage was induced in rats by administering ethanol (5 g/kg, 20\% w/v p.o.) once daily for 21 days. GIE at $400 \mathrm{mg} / \mathrm{kg}$ and $800 \mathrm{mg} / \mathrm{kg}$ and the reference drug silymarin $(200 \mathrm{mg} / \mathrm{kg})$ were administered orally for 28 days to ethanol treated rats, this treatment beginning 7 days prior to the commencement of ethanol administration.

Levels of marker enzymes (aspartate aminotransferase (AST), alanine aminotransferase (ALT) and alkaline phosphatise (ALP)), triglyceride (sTG), albumin (Alb) and total protein (TP) were evaluated in serum. Antioxidant parameters (reduced glutathione (GSH), superoxide dismutase (SOD), catalase (CAT), glutathione peroxidase $(\mathrm{GPx})$ and glutathione reductase (GR)), hepatic triglycerides (hTG) and the lipid peroxidation marker malondialdehyde (MDA) were determined in liver. GIE and silymarin elicited significant hepatoprotective activity by attenuating the ethanol-elevated levels of AST,
ALT, ALP, sTG, hTG and MDAand restored the ethanol-depleted levels of GSH, SOD, CAT, GPx, GR, Alb and TP. GIE $800 \mathrm{mg} / \mathrm{kg}$ demonstrated greater hepatoprotection than GIE $400 \mathrm{mg} / \mathrm{kg}$. The present findings indicate that hepatoprotective effects of GIE in ethanolinduced oxidative damage may be due to an augmentation of the endogenous antioxidants and inhibition of lipid peroxidation in liver ${ }^{38}$.

30. Glinus oppositifolius: The ethanolic extract $(80 \%)$ aerial part of Glinus oppositifolius (Family of Molluginaceae) was prepared and tested for its hepatoprotective effect against paracetamol-induced hepatitis in rats. Alteration in the levels of biochemical markers of hepatic damage like SGOT, SGPT, ALP, cholesterol and bilirubin were tested in both treated and untreated groups. Paracetamol (2 $\mathrm{g} / \mathrm{kg}$ ) has enhanced the SGOT, SGPT, ALP, cholesterol and bilirubin levels. Treatment with ethanolic extract of aerial part of $G$. oppositifolius $(200 \mathrm{mg} / \mathrm{kg}$ and $400 \mathrm{mg} / \mathrm{kg}$ ) has reverse back the altered levels of biochemical markers to the near normal levels in the dose dependent manner ${ }^{39}$.

\section{Kigelia africana and Anogeissus accuminata:} The methanolic extracts of Kigelia africana (Family of Bignoniaceae) and Anogeissus accuminata (Family of Combretaceae) against paracetamol induced liver damage in rats. The methanolic extracts of Kigelia africana (200 $\mathrm{mg} / \mathrm{kg}$ ) and Anogeissus accuminata (300 $\mathrm{mg} / \mathrm{kg}$ ) was administered orally to the animals with hepatotoxicity induced by paracetamol (3 $\mathrm{gm} / \mathrm{kg})$. Silymarin $(25 \mathrm{mg} / \mathrm{kg})$ was given as reference standard. All the test drugs were administered orally by suspending in $1 \%$ Tween-80 solution. The plant extract was effective in protecting the liver against the injury induced by paracetamol in rats. This was evident from significant reduction in serum enzymes alanine aminotransferase (ALT), aspartate aminotransferase (AST), alkaline phosphatase (ALP) and Total bilirubin (TB) ${ }^{40}$.

32. Leacus cephalotes: The methanolic extract of the plant Leacus cephalotes (Family of Lamiaceae) for hepatoprotective activity against carbon tetra chloride-induced liver damage in Swiss albino mice and antioxidant 
activity by hydrogen peroxide scavenging assay in dose dependant manner. Methanolic extract of plant Leacus cephalotes investigate for hepatoprotective activity against carbon tetrachloride induced hepatotoxicity using biochemical markers Serum glutamate pyruvate transaminase- SGPT, Serum glutamate oxaloacetate transaminase- SGOT, serum bilirubin, Serum alkaline phosphatase- SALP. The hepatoprotective activity was also supported by histopathological studies of liver tissue.

Antioxidant activity investigated by in vitro hydrogen peroxide scavenging assay. Biochemical studies of blood samples of methanolic extract of Leacus Cephalotes showed significant decrease in the levels of serum markers, indicating the protection of hepatic cells, the extract of above plant could afford significant protection against $\mathrm{CCl} 4$ induced hepatocellular injury. The methanolic extract from Leucas cephalotes exerts significant antioxidant effects, which were comparable with standard drugs. Administration of methanolic extract of the plant Leacus Cephalotes protect the liver from toxic effects of carbon tetra chloride by reducing the elevated levels of Serum enzymes which shows the significant protection against $\mathrm{CCl} 4$ induced hepatocellular injury ${ }^{41}$.

33. Litchi chinensis: The chloroform and methanol extracts from Litchi chinensis (Family of Sapindaceae) leaf were evaluated for their protective effects on paracetamol-induced liver damage in Wistar albino rats. Serum biochemical parameters viz. serum glutamate oxaloacetate transaminase (SGOT), serum glutamate pyruvate transaminase (SGPT), serum alkaline phosphatase (SALP), total protein, bilirubin, cholesterol, triglycerides; and liver biochemical parameters such as lipid peroxidation, reduced glutathione (GSH) content and catalase (CAT) activities were evaluated. All biochemical observations indicated that both the test extracts exerted significant hepatoprotective efficacy against paracetamol-induced hepatic damage in rats. The methanol extract was found to be more effective than chloroform extract.
Therefore, from the present study it can be concluded that $L$. chinensis leaf had remarkable hepatoprotective activity in rats ${ }^{42}$.

34. Luffa acutangula: The hepatoprotective activity of hydroalcoholic extract of Luffa acutangula (HAELA) (Family of Cucurbitaceae) against carbon tetrachloride $\left(\mathrm{CCl}_{4}\right)$ and rifampicin-induced hepatotoxicity in rats was evaluated and probable mechanism(s) of action has been suggested. Administration of standard drug- silymarin and HAELA showed significant hepatoprotection against $\mathrm{CCl}_{4}$ and rifampicin induced hepatotoxicity in rats. Hepatoprotective activity of HAELA was due to the decreased levels of serum marker enzymes viz., (AST, ALT, ALP and LDH) and increased total protein including the improvement in histoarchitecture of liver cells of the treated groups as compared to the control group.

HAELA also showed significant decrease in malondialdehyde (MDA) formation, increased activity of non-enzymatic intracellular antioxidant, glutathione and enzymatic antioxidants, catalase and superoxide dismutase. Results of this study demonstrated that endogenous antioxidants and inhibition of lipid peroxidation of membrane contribute to hepatoprotective activity of HAELA ${ }^{43}$.

35. Madhuca longifolia: In vivo hepatoprotective effect of Ethanolic extract of Madhuca longifolia (Family of Sapotaceae) leave (EEMLL) extract was evaluated using DGalactosamine (GalN) induced acute hepatotoxicity in rats. Pretreatment with EEMLL $(200 \mathrm{mg} / \mathrm{kg} \& 400 \mathrm{mg} / \mathrm{kg}$ ) for seven days significantly reduced the impact of Galactosamine toxicity (400mg/kg,i.p) on the serum markers of liver damage. Furthermore, considering the well-known implication of free radicals in tissue injury, in vitro antioxidant properties of the extract were determined with a view to suggest the possible mechanism of activity. Therefore, presented result suggests that EEMLL is potent hepatoprotective agent that could protect liver against the acute injury and this ability might be attributed to its antioxidant potential ${ }^{44}$. 
36. Melia azedarach: The hepatoprotective activity of Melia azedarach L (Family of Meliaceae) leaves extracts against simvastatin induced hepatotoxicity. The phytochemical screening was carried on the leaves extracts of Melia azedarach revealed the presence of some active ingredients such as Alkaloids, Tannins, Sponginess, Phenols, glycosides, steroids, terpenoids and flavonoids. Leaves of Melia azedarach was successively extracted with ethanol against simvastatin (20mg/kg.p.o) induced hepatotoxicity using Standard drug Silymarin $(25 \mathrm{mg} / \mathrm{kg})$.

There was a significant changes in biochemical parameters (increases in serum glutamate pyruvate transaminase (SGPT), Serum glutamate oxaloacetate transaminase (SGOT), alanine phosphatase (ALP), serum bilirubin and decrease the total proteins content.) in simvastatin treated rats, which were restored towards normalization in Melia azedarach (300 $\mathrm{mg} / \mathrm{kg}$ and $500 \mathrm{mg} / \mathrm{kg}$ ) treated animals. Thus the present study ascertains that the leaf extract of Melia azedarach possesses significant hepatoprotective activity ${ }^{45}$.

37. Mentha arvensis: The ethanol, chloroform and aqueous leaf extracts of Mentha arvensis (Family of Lamiaceae) against induced by $\mathrm{CCl}_{4}$ and the biochemical parameters such as serum glutamate pyruvate transminase (sGPT), serum glutamate oxaloacetate transaminase (sGOT), alkaline phosphatase (sALP), serum bilirubin (sB) and histopathological changes in liver were studied along with silymarin as standard Hepatoprotective agents. Treatment of the rats with chloroform, ethanol and aqueous extract with $\mathrm{CCl}_{4}$ administration caused a significant reduction in the values of sGOT, sGPT, sALP and $\mathrm{sB}(\mathrm{P}<0.01)$ almost comparable to the silymarin. The Hepatoprotective was confirmed by histopathological examination of the liver tissue of control and treated animals ${ }^{46}$.

38. Musa paradisiacal: The hepatoprotective activity of alcoholic and aqueous extracts of stem of $M$. paradisiaca (Family of Musaceae) was demonstrated by using two experimentally induced hepatotoxicity models. Administration of hepatotoxins $\left(\mathrm{CCl}_{4}\right.$ and paracetamol) showed significant biochemical and histological deteriorations in the liver of experimental animals. Pretreatment with alcoholic extract $(500 \mathrm{mg} / \mathrm{kg})$, more significantly and to a lesser extent the alcoholic extract $(250 \mathrm{mg} / \mathrm{kg})$ and aqueous extract $(500 \mathrm{mg} / \mathrm{kg})$, reduced the elevated levels of the serum enzymes like serum glutamic-oxaloacetic transaminase (SGOT), serum glutamic pyruvic transaminase (SGPT), alkaline phosphatase (ALP) and bilirubin levels and alcoholic and aqueous extracts reversed the hepatic damage towards the normal, which further evidenced the hepatoprotective activity of stem of $M$. Paradisiacal $^{47}$.

\section{Meconopsis integrifolia: The in vitro} antioxidant property of Meconopsis integrifolia ethanolic extract (MIE) (Family of Papaveraceae) was investigated by employing various established systems. Rats with carbon tetrachloride (CCl4)-induced liver injury were used to assess the hepatoprotective and antioxidant effect of MIE in vivo. The level or activity of alkaline phosphatase (ALP), glutamate pyruvate transaminase (ALT), aspartate aminotransferase (AST), and total bilirubin (TB) in the blood serum and thiobarbituric acid reactive substances (TBARS), superoxide dismutase (SOD), catalase (CAT), and glutathione (GSH) in the liver and kidney of the rats were assayed using standard procedures ${ }^{48}$.

40. Melastoma malabathricum: The present study aimed to determine the hepatoprotective activity of a methanol extract of Melastoma malabathricum leaves (MEMM) (Family of Melastomataceae) using two established rat models. Ten groups of rats $(n=6)$ were given a once-daily administration of $10 \%$ dimethyl sulfoxide (negative control), $200 \mathrm{mg} / \mathrm{kg}$ silymarin (positive control), or MEMM (50, 250 , or $500 \mathrm{mg} / \mathrm{kg}$ ) for 7 days followed by induction of hepatotoxicity either using paracetamol or carbon tetrachloride. Blood samples and livers were collected for biochemical and microscopic analysis. Based on the results obtained, MEMM exhibited a significant $(\mathrm{p}<0.05)$ hepatoprotective activity against both inducers, as indicated by an improvement in the liver function test. 
These observations were supported by the histologic findings. In conclusion, $M$. malabathricum leaves possessed hepatoprotective activity, which could be linked to their phytochemical constituents and antioxidant activity; this therefore requires further in-depth studies ${ }^{49}$.

41. Melochia corchorifolia: The hepatoprotective activity concluded that $M$. corchorifolia (Family of Malvaceae) aerial part extracts was assessed against $\mathrm{CCl} 4$ induced liver intoxication in rats. The extracts produced concentration dependent percentage protection in decrease of serum enzymes and percentage inhibition on free radicals. Among all extracts methanol extract showed better activity with percentage protection of SGOT (78.98\%), SGPT $(79.65 \%)$, ALP $(82.48 \%)$ and total bilirubin $(80.0 \%)$ levels against $\mathrm{CCl}_{4}$ liver intoxication and also methanolic extract showed better activity with IC50 values on superoxide, hydroxyl and DPPH radicals were $127 \mu \mathrm{g}, 240 \mu \mathrm{g}$ and $179 \mu \mathrm{g}{ }^{50}$.

42. Murraya koenigii: Therapeutic potentials of aqueous curry leaf Murraya koenigii (Family of Rutaceae) extract (CuLE) against lead induced oxidative damage in hepatic tissue. Rats were intraperitoneally injected with lead acetate $(15 \mathrm{mg} / \mathrm{kg}$ body weight). Another group was pre-treated with CuLE (50 mg / kg, fed orally).The positive control group was fed CuLE (50 mg / kg), and the control animals received vehicle treatment i.p. for 7 consecutive days. Concentration of lead in liver was estimated by AAS study. The alterations in the activity of the different bio-markers of hepatic damage, biomarkers of oxidative stress, activities of the antioxidant and some of the mitochondrial enzymes were studied.

Histomorphology and alteration in tissue collagen level was studied through H-E staining and Sirius red staining respectively. Quantification of tissue collagen content was evaluated using confocal microscopy. The results indicate that the CuLE ameliorates leadinduced hepatic damage in experimental rats by antioxidants present in the extract. CuLE may have future therapeutic relevance in the prevention of lead-induced hepatotoxicity in humans exposed occupationally or environmentally to this toxic heavy metal and may be used for development of new hepatoprotective drugs of herbal origin with less cytotoxic effects ${ }^{51}$.

43. Plectranthus amboinicus: The ethanolic extract of leaves of Plectranthus amboinicus (Family of Lamiaceae) possesses hepatoprotective activity against paracetamol induced hepatotoxicity in rats. Six groups of wistar rats were used in the study. The two control groups received gum acacia and paracetamol orally respectively. The three test groups were treated orally with paracetamol followed by 300, 600 and $900 \mathrm{mg} / \mathrm{kg}$ of ethanolic extract respectively. The sixth group (standard hepatoprotective) received paracetamol followed by $\mathrm{N}$-acetylcysteine 100 $\mathrm{mg} / \mathrm{kg}$ orally. The hepatoprotective activity was evaluated by estimating serum alanine aminotransferase, aspartate aminotransferase, alkaline phosphatase, tissue malondialdehyde levels and by histopathological analysis of the liver tissue ${ }^{52}$.

44. Pippali piper longum: The hepatoprotective activity in paracetamol induced hepatotoxic mice model. Piperine was extracted from Pippali Piper Longum (Family of Piperaceae). Solvent evaporation method was employed to fabricate the microspheres. Optical microscopy demonstrated that the formulation was spherical and had smooth texture with no drug crystals or microsphere aggregation.

Formulations containing $2 \mathrm{mg}$ piperine were administered orally to the animal model. In paracetamol induced hepatotoxic mice model, SGOT and SGPT level demonstrated no significant elevation in the blood by the microspheres formulation. The histopathology and enzyme level results suggested that microsphere formulation can passively target hepatoprotective drug to the liver ${ }^{53}$.

45. Spilanthes paniculata: The hepatoprotective effect of Spilanthes paniculata (Family of Asteraceae) flower extracts against paracetamol-induced liver damage. The study was conducted in 36 male Wistar rats of either sex, and six groups were established. 
While the first group was maintained as normal control (NC, distilled water), Groups 2-6 were administered $3 \mathrm{gm} / \mathrm{kg}$ Paracetamol (PAR) for 2 day, $100 \mathrm{mg} / \mathrm{kg}$ Silymarin (SMR), $500 \mathrm{mg} / \mathrm{kg}$ Methanolic extract (MESP), Petroleum ether extract (PEESP), Ethyl acetate extract of $\mathrm{S}$. paniculata (EAESP) suspended in $0.5 \%$ tween 80 plus PAR respectively, PAR was administered in the same schedule as in group 2 , the treatment with silymarin and extracts was given for 10 days orally, respectively. It was shown that PAR significantly increased serum ALT, AST, ALP, liver MDA levels $(\mathrm{P}<0.01)$ and significantly decreased liver GSH, CAT, SOD activity $(\mathrm{P}<0.01)$, when compared with the normal control group (NC).

On the other hand, statistical significant $(\mathrm{P}<0.01)$ changes were observed in the biochemical parameters of the group which was administered SMR, PEESP and EAESP. Compared with the pathological changes observed in the liver congested sinusoids and centrilobular necrosis, in the group which was administered paracetamol alone (PAR), lesions were determined to be less severe particularly in the group (PEESP and EAESP). The study had revealed that administration of PEESP \& EAESP offered a therapeutic potential for the treatment of hepatotoxicity induced by paracetamol via regulation of endogenous antioxidant system in liver ${ }^{54}$.

46. Stevia rebaudiana: The leaves of Stevia rebaudiana Bert.(Family of Asteraceae) is commonly known as hypocaloric biosweeteners. It can be used in multiple health diseases and traditionally the leaves of Stevia are used as sugar substitute. The present study was carried out to evaluate the hepatoprotective activity of Stevia rebaudiana leaves against thioacetamide-induced (s.c.) hepatotoxicity.

Aqueous leaves extract of Stevia rebaudiana (AESR) at dose levels of 200 and 400 $\mathrm{mg} / \mathrm{kg} /$ day were evaluated. Oral administration of Stevia leaves extract at $400 \mathrm{mg} / \mathrm{kg}$ resulted in a significant reduction in aspartate transaminase, (AST, 131.1 $\pm 3.0 \mathrm{IU} / \mathrm{L})$, alanine aminotransferase (ALT, 62.2 $\pm 1.8 \quad \mathrm{IU} / \mathrm{L})$, gamma glutamyl transpeptidase (GGT, 13.0 $\pm 0.3 \mathrm{IU} / \mathrm{L}$ ), alkaline phosphatase (ALP,
197.4 $\pm 3.2 \mathrm{IU} / \mathrm{L})$ and total bilirubin $(0.23 \pm 0.0$ $\mathrm{mg} / \mathrm{dL}$ ) compared to control. The glutathione (GSH) and MDA levels of the liver tissue samples were also measured. Histology of the liver sections of the animals treated with the extract also showed dose-dependent reduction of necrosis. The present investigation revealed the hepatoprotective activity of the aqueous leaves extract of Stevia rebaudiana against thioacetamide induced hepatotoxicity ${ }^{55}$.

47. Swietenia mahogany: The aqueous leaf extract of Swietenia mahogani (Family of Maliaceae) in chronic alcohol-induced liver injury in rats. The animals were given increasing concentrations $(10 \%$ ethanol $(\mathrm{v} / \mathrm{v})$ in water for 1 week, $20 \%$ (v/v) for another 2 weeks and $30 \%$ (v/v) for 9 weeks) per os daily. Treatment with the extract (250 and $500 \mathrm{mg} / \mathrm{kg}$ ) was instituted $6 \mathrm{~h}$ after given the alcohol for the same period the alcohol intake lasted. Thereafter, the activities of alanine aminotransferase (ALT), aspartate amino transferase (AST) and alkaline phosphatase (AP) were assayed in the serum. The levels of other biochemical markers of organ damage such as total bilirubin and creatinine, as well as pentobarbitone sleeping time were determined.

Histological examination of the liver was also performed. The extract at all doses significantly $(\mathrm{P}<0.05)$ reduced the serum activities of ALT, AST, AP, serum levels of bilirubin and creatinine in comparison with the negative control that received only alcohol. The duration of pentobarbital induced hypnosis was also significantly shortened. The histopathological result showed significant $(\mathrm{P}<0.05)$ protection in the extract treated groups when compared with the group that received alcohol alone ${ }^{56}$.

48. Tridax procumbens: The potential of an aqueous extract of the leaves of Tridax procumbens (Family of Asteraceae) to protect against carbon tetrachloride-induced liver injury was investigated in Wistar albino rats. The carbon tetrachloride was prepared 1:5 (v:v) in olive oil, and administered subcutaneously at $1 \mathrm{~mL} / \mathrm{kg}$ body weight. The extract was administered to both normal and carbon tetrachloride treated rats at 100, 200, and 300 $\mathrm{mg} / \mathrm{kg}$. 
On gas chromatographic analysis of the flavonoid fraction of the aqueous crude extract, twenty-three known flavonoids were detected, consisting mainly of apigenin (29.00\%), quercetin (21.67\%), kaempferol (11.20\%), (-)epicatechin $(6.38 \%)$, naringenin $(4.82 \%),(+)-$ catechin $(3.28 \%)$, biochanin $(3.21 \%)$, robinetin $(3.13 \%)$, diadzein $(2.57 \%)$, and nobiletin $(2.07 \%)$. Compared to test control, the treatment dose dependently significantly lowered $(P<0.05)$ alkaline phosphatase $(54.91$ $100.52 \%)$, aspartate transaminase (37.74$64.79 \%$ ), and alanine transaminase (32.96$57.82 \%)$ activities.

The plasma total bilirubin and total protein levels of the treated animals were lower though not significantly. Histopathological studies provided supportive evidence for the biochemical analysis. The results of this study indicated that treatment with the plant extracts protects the liver against carbon tetrachloride induced hepatotoxicity, thus supporting the use of $T$. procumbens in African traditional health care for the treatment of liver problems ${ }^{57}$.

49. Vernonia amygdalina: The possible antioxidant properties of Vernonia amygdalin (Family of Asteraceae) leaves in preventing damages to the liver and kidney of albino rats. To investigate this, carbon tetrachloride $(\mathrm{CCl} 4)$ was injected into rats in order to induce liver and kidney damage. The rats were simultaneously given oral doses $(20 \mathrm{mg} / \mathrm{kg}$ and $60 \mathrm{mg} / \mathrm{kg}$ body weight) of methanolic extract of leaves of $V$. amygdalin. The effects of these treatments on some liver and kidney enzymes were evaluated.

Administration of $\mathrm{CCl} 4$ alone to rats significantly $(P<0.05)$ reduced the activities of liver ALT and AST by $71 \%$ and $60 \%$ respectively. The values for kidney AST and ALT are $47 \%$ and $80 \%$ respectively. Simultaneous treatment of $\mathrm{CCl} 4$ injection with oral administration of $20 \mathrm{mg} / \mathrm{kg}$ and $60 \mathrm{mg} / \mathrm{kg}$ body weight of the methanolic extract significantly reversed $(P<0.05)$ these changes in both the liver and kidney. The activities of liver and kidney GGT were considerably reduced by $\mathrm{CCl} 4$ administration and were also reverse by the plant extract.
The present findings suggest that the extract may probably possess components that are hepatoprotective ${ }^{58}$.

50. Vigna mungo: The acute administration of ethanol causes liver damage, the present study was undertaken to investigate the hepatoprotective activity of methanolic extract of seeds of Vigna mungo (Linn) Hepper (MEVM) (Family of Fabaceae) against ethanolinduced hepatic damage in adult albino rats of either sex.

The hepatoprotective effect was evaluated on the basis of liver function parameters such as increased (liver weight and volume), elevated serum enzyme levels (glutathione pyruvate transaminase, oxaloacetate transaminase, alkaline phosphatase and total bilirubin) and increased (thiopentone induced sleeping time). The MEVM treated rats produced statistically significant protection. The results were also

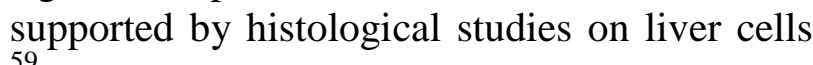
59 .

51. Vitis vinifera: The ethanolic extract of the root of Vitis vinifera (Family of Vitaceae) was evaluated for hepatoprotective activity in rats with liver damage induced by carbon tetrachloride. The extract at an oral dose of 200 $\mathrm{mg} / \mathrm{kg}$ exhibited a significant protective effect by lowering the serum levels of SGPT, SGOT, alkaline phosphatase and total bilirubin. The extract at this dose also increases the level of total protein. These biochemical observations were supplemented by histopathological examination of liver sections. The activity of extract was also comparable to that of silymarin, a known hepatoprotective drug ${ }^{60}$.

ACKNOWLEDGEMENT: The authors are grateful thanks to Institute of Pharmacy, Department of Pharmacognosy, Bundelkhand University Jhansi, (India), for assistance in Literature collection and for other facilities during the preparation of this manuscript.

\section{REFERENCES:}

1. Dienstag JL, Isselbacher KJ. Toxic and drug-induced hepatitis, 15th edn. Chapter 296, In: Harrison's Principles of Internal Medicine. Braunwald $\mathrm{E}$, et al, The McGraw-Hill Companies, In, 2001; 2:737-1742. 
2. Chattopadhyay RR, Bhattacharyya SK, Terminalia chebula: An update, Pharmacog 2007; 1(1):439-45.

3. Hikino H, Kiso Y. Natural products for liver diseases. Economic and Medicinal Plant Research. Vol.2, Academic Press, London 1988; p 39-67.

4. Roy SD, Das S, Shil D, Dutta KN. Herbal hepatoprotective agents: A review.World J Pharma Res 2012; 1(2): 87-99.

5. Bone K, Mills S. Principles and Practices of Phytotheraphy. British J Phytother 2001; 12(2): 107-13.

6. Porchezhian E, Ansari SH. Hepatoprotective activity of Abutilon indicum on experimental liver damage in rats. Phytomed Int J Phytother Phytopharmacol 2005; 12(1): 62-74.

7. Visen PK, Shukla B, Patnaik GK, Dhawan BN. Andrographolide protects rat hepatocytes against paracetamol induced damage. J Ethnopharmacol 1993; 40:131-136.

8. Handa SS, Sharma A. Hepatoprotective activity of Andrographolide from Andrographis paniculata against carbon tetrachloride. Ind J Med Res 1990; 92: 276-92.

9. Dahanukar SA, Kulkarni RA, Rege NN. Pharmacology of medicinal plants and natural product. Ind $J$ Pharmacol. 2000; 32: S81-S118.

10. Wu JB, Lin WL, Hsieh CC, Ho HY, Tsay HS, Lin WC. The hepatoprotective activity of kinsenoside from Anoectochilus formosanus. Phytother Res 2007; 21:58-61.

11. Chattopadhyay RR, Sarkar SK, Ganguly S, Banerjee RN, Basu TK, Mukherjee A. Hepatoprotective activity of Azadirachta indica leaves on paracetamol induced hepatic damage in rats. Indian J Exp Biol 1992; 30(8):738-40.

12. Manokaran S, Jaswanth A, Sengottuvelu S, Nandhakumar J, Duraisamy R, Karthikeyan D, Mallegaswari R. Hepatoprotective activity of Aerva Lanata Linn. against paracetamol induced hepatotoxicity in rats, Res J Pharm Tech 2008; 1(4): 398-400.

13. Jayasekhar $\mathrm{P}$, Mohanan PV, Rathinam K. Hepatoprotective activity of ethyl acetate extract of Acacia catechu, Indian J Pharmacol 1997; 29: 426-428.

14. Wahid AM, Salunkhe VR, Bhise SB. Hepatoprotective activity of hydroalcoholic extract of leaves of Alocasia indica (Linn.). Indian J Exp Bio 2009; 47: 816-821.

15. Hussain ZA, Amresh GA, Singh SB, Rao CVA, Hepatoprotective activity of Amaranthus spinosus in experimental animals. Food Chem Toxicol 2008; 46: 3417-3421.

16. Hurkadale PJ, Shelar PA, Palled SG, Mandavkar YD, Khedkar AS. Hepatoprotective activity of Amorphophallus paeoniifolius tubers against paracetamol-induced liver damage in rats. Asian Pac J Trop Biomed 2012; S238S242.

17. Sharma HD. Hepatoprotective potential of Aloe barbadensis Mill. against carbon- tetrachloride induced hepatotoxicity. Int J Res Pharma Biomed Sci 2012; 3(3): 1119- 1124.

18. Allam RM, Selim DA, Ghoneim AI, Radwan MM, Nofal SM, Khalifa AE, Sharaf OA, Toaima SM, Asaad AM, ElSebakhy NA. Hepatoprotective effects of Astragalus kahiricus root extract against ethanol-induced liver apoptosis in rats. Chin J Nat Med 2013 4: 354-361.

19. Balaji P, Kishore G, Verma Y. In-vivo hepatoprotective activity of Barleria cristata L. ethanolic leaf extracts against $\mathrm{CCl}_{4}$ induced hepatic injury in wistar rats. Int $J$ Comprehen Pharm 2013; 4(4): 1-6.

20. Duraiswamy B, Satishkumar MN, Gupta S, Rawat M, Porwal O, Murugan R. Hepatoprotective activity of Betula utilis bark on D-galactosamine induced hepatic insult. World J Pharm Pharma Sci 2012; 1(1): 456-471.
21. Jayavelu A, Natarajan A, Sundaresan S, Devi K, Senthil KB. Hepatoprotective activity Boerhavia diffusa Linn. (Nyctaginaceae) against ibuprofen induced hepatotoxicity in wistar albino rats. Int J Pharma Res \& Revi 2013; 2(4): $1-8$.

22. Akram E, Pejman M, Maryam B, Jalal Z. Hepatoprotective activity of Cinnamon ethanolic extract against $\mathrm{CCl}_{4}$ induced liver injury in rats. EXCLI J 2012; 11: 495-507.

23. Nayak DP, Dinda SC, Swain PK, Kar B, Patro VJ. Hepatoprotective activity against $\mathrm{CCl}_{4}$-induced hepatotoxicity in rats of Chenopodium album aerial parts. J Phytother Pharmacol 2012; 1(2): 33-41.

24. Konate K, Ouedraogo M, Ouattara MB, Dibala IC, Mavoungou JF, Lepengue AN, Souza A, et al. Hepatoprotective activity of aqueous acetone extract from Cienfuegosia digitata Cav. (Malvaceae) against alcohol hepatotoxicity in albinos wistar rats. Res J Appl Sci Eng Technol 2012; 4(12): 1637-1641.

25. Dar AI, Saxena RC, Bansal S. Hepatoprotection: a hallmark of Citrullus colocynthis L. against paracetamol induced hepatotoxicity in swiss albino rats. American $J$ Plant Sci 2012; 3: 1022-1027.

26. Madhavi P, Vakati K, Rahman H. Hepatoprotective activity of Citrullus lanatus seed oil on $\mathrm{CCl}_{4}$ induced liver damage in rats. Scholars Aca J Pharm ;1(1): 30-33.

27. Pillai KK, Chidambaranathan N, Halith MM, Jayaprakash S. Hepatoprotective activity of Cnidoscolus chayamansa against rifampicin and isoniazide induced toxicity in wistar rats. Res J Pharma Bio Chem Sci 2012; 3(2): 577-585.

28. Jeong SC, Kim SM, Jeong YT, Song $\mathrm{CH}$ Hepatoprotective effect of water extract from Chrysanthemum indicum L. flower. Chin Med 2013; 8(1): 7.

29. Salama SM, Abdulla MA, AlRashdi AS, Ismail S, Alkiyumi SS, Golbabapour S. Hepatoprotective effect of ethanolic extract of Curcuma longa on thioacetamide induced liver cirrhosis in rats. BMC Complement Altern Med 2013; 5(13): 56.

30. Datta S, Dhar Susmita, Nayak SS, Dinda C. Hepatoprotective activity of Cyperus articulates Linn.against paracetamol induced hepatotoxicity in rats. $J$ Chem Pharm Res 2013; 5(1): 314-319.

31. Jayadevaiah KV, Ishwar BK, Joshi AB, Vijaykumar MMJ, Rawal P. Hepatoprotective activity of Desmodium oojeinense (Roxb.) H. Ohashi against paracetamol induced hepatotoxicity. Asian J Pharm Hea Sci 2012; 2(2): 312315.

32. Narayanan JJ, Winka JJ, Rajkumar M, Senthil KK. Study of hepatoprotective activity of Ecbolium viride (Forssk.) Alston. Iosr J Pharma 2012; 2(2): 157-161.

33. Vijayarathna S, Jothy SL, Ping KY, Latha LY, Othman N, Sasidharan S. In vitro antioxidant activity and hepatoprotective potential of Elaeis guineensis leaf against paracetamol induced damage in mice. Int J Chem Eng Appl 2012; 3(4): 293-296.

34. Wan YH, Swee KY, Chai LH, Rahim RA, Noorjahan BA. Hepatoprotective activity of Elephantopus scaber on alcohol-induced liver damage in mice. Evidence-Based Complemen Alter Med 2012; 1-8.

35. Shinde M, Shete RV, Kore KJ, Attal AR. Hepatoprotective activity of Ficus bengalensis Linn leaves. Curr Pharma Res 2(2): 2012; 503-507.

36. Dar AI, Saxena RC, Bansal SK. Assessment of hepatoprotective activity of fruit pulp of Feronia limonia (Linn.) against paracetamol induced hepatotoxicity in albino rats. J Nat Prod Plant Resour 2012; 2(2): 226-233.

37. Panda V, Ashar H, Srinath S. Antioxidant and hepatoprotective effect of Garcinia indica fruit rind in 
ethanol induced hepatic damage in rodents. Interdiscip Toxicol 2012; 5(4): 207-213.

38. Sahu SK, Das D, Tripathy NK. Hepatoprotective activity of aerial part of Glinus oppositifolius L. against paracetamol-induced hepatic injury in rats. Asian J Pharm Tech 2012; 2(4): 154-156.

39. Hemamalini K, Preethi B, Bhargav A, Vasireddy U. Hepatoprotective activity of Kigelia africana and Anogeissus accuminata against paracetamol induced hepatotoxicity in rats. Int J Pharm Biomed Res 2012; 3(3): 152-156.

40. Itoria P, Jain G. To investigate Leucas Cephalotes for its antioxidant and hepatoprotectiv activity against $\mathrm{CCl}_{4}$ Induced hepatotoxicity in swiss albino mice. Int J Pharma Bio Sci 2012; 3(2): 366-373.

41. Basu S, Haldar N, Bhattacharya S, Biswas S, Biswas M. Hepatoprotective activity of Litchi chinensis leaves against paracetamol-induced liver damage in rats. Am-Euras $J$ Sci Res 2012; 7(2): 77-81.

42. Jadhav V B, Thakare V N, Suralkar AA, Deshpande AD, Naik SR. Hepatoprotective activity of Luffa acutangula against $\mathrm{CCl}_{4}$ and rifampicin induced liver toxicity in rats: A biochemical and histopathological evaluation. Indian $\mathbf{J}$ Exp Bio 2010; 48(8): 822-829.

43. Roy SP, Gupta R, Kannadasan T. Hepatoprotective activity of Ethanolic extract of Madhuca longifolia leaves on D-galactosamine induced liver damage in rats. $J$ Chem Pharm sci 2012; 5: 205-209.

44. Rao AS, Ahmed MF, Ibrahim M. Hepatoprotective activity of Melia azedarach leaf extract against simvastatin induced hepatotoxicity in rats. J Appl Pharma Sci 2012; 2(7): 144-148.

45. [46] Patil K, Mall A. Hepatoprotective activity of Mentha arvensis Linn. leaves against $\mathrm{CCl}_{4}$ induced liver damage in rats. Asian Pac J Trop Dis 2012; S223-S226.

46. Nirmala M, Girija K, Lakshman K, Divya $T$. Hepatoprotective activity of Musa paradisiaca on experimental animal Models. Asian Pac J Trop Biomed 2012; 11-15.

47. Zhou G, Chen Y, Liu S, Yao X, Wang Y. In vitro and in vivo hepatoprotective and antioxidant activity of ethanolic extract from Meconopsis integrifolia (Maxim.) Franch $J$ Ethnopharmacol 2013; 148(2): 664-670.

48. Kamisan FH, Yahya F, Ismail NA, Din SS, Mamat SS, Zabidi $\mathrm{Z}$ et al. Hepatoprotective activity of methanol extract of Melastoma malabathricum leaf in rats. $J$ Acupunct Meridian Study 2013; 6(1): 52-55.

49. Rao BG, Rao YV, Rao TM. Hepatoprotective and antioxidant capacity of Melochia corchorifolia extracts. Asian Pac J Trop Med 2013; 7: 537-543.

50. Ghosh D, Firdaus SB, Mitra E, Dey M, Chattopadhya A, Pattari SK et al. Hepatoprotective activity of aqueous leaf extract of Murraya koenigii against lead-induced hepatotoxicity in male wistar rat. Int J Pharm Pharm Sci 2013; 5(1): 285-295.

51. Shenoy S, Kumar H, Thashma, Nayak V, Prabhu K, Pai P, et al. Hepatoprotective activity of Plectranthus amboinicus against paracetamol induced hepatotoxicity in rats. Int J Pharmacol \& Clin Sci 2012; 1: 32-38.

52. Sahu P, Bhatt A, Chaurasia A, Gajbhiye V. Enhanced hepatoprotective activity of Piperine loaded chitosan microspheres. Int J Drug Dev Res 2012; 4(4): 229-233.

53. Syed AA, Shukla M, Khan WS. Hepatoprotective activity of Spilanthes paniculata flower extracts on liver damage induced by paracetamol in rats. Der Pharmacia Sinica 2012; 3(6): 738-744.

54. Kuntal DAS, Kathiriya AK. Hepatoprotective activity of Stevia rebaudiana Bert. leaves against thioacetamide induced toxicity. Turk J Pharm Sci 2012; 9(3): 343-352.

55. Udem S, Nwaogu I, Onyejekwe O. Evaluation of hepatoprotective activity of aqeous leaf extract of Swietenia mahogani (Maliaceae) in chronic alcoholinduced liver injury in rats. Maced J Med Sci 2011; 4(1): 31-36.

56. Ikewuchi JC. An aqueous extract of the leaves of Tridax procumbens Linn (Asteraceae) protected against carbon tetrachloride induced liver injury in wistar rats. The Pac J Sci Tech 2012; 13(1): 519-527.

57. Minari JB. Hepatoprotective effect of methanolic extract of Vernonia amygdalina. J Nat Prod 2012; 5: 188-192.

58. Nitin M, Ifthekar S, Mumtaz M. Hepatoprotective activity of methanolic extract of Vigna mungo (Linn.) Hepper in ethanol-induced hepatotoxicity in rats. RGUHS J Pharm Sci 2012; 2(2): 62-67.

59. Sharma SK, Vasudeva S, Vasudeva N. Hepatoprotective activity of Vitis Vinifera root extract against carbon tetrachloride-induced liver damage in rats. Acta Poloniae Pharma Drug Res 2012; 69(5): 933-937.

How to cite this article:

Soni RK, Dixit V, Irchhaiya R and Alok S: Potential Herbal Hepatoprotective Plants: An Overview. Int J Pharm Sci Res 2014; 5(3): 774-89.doi: 10.13040/IJPSR.0975-8232.5(3).774-89

All ( 2013 are reserved by International Journal of Pharmaceutical Sciences and Research. This Journal licensed under a Creative Commons Attribution-NonCommercial-ShareAlike 3.0 Unported License.

This article can be downloaded to ANDROID OS based mobile. Scan QR Code using Code/Bar Scanner from your mobile. (Scanners are available on Google Playstore) 